\title{
A speciation model linking the fate of carbon and hydrogen during core - magmaocean equilibration
}

FABRICE GAILLARD ${ }^{1}$, MALAVERGNE MALAVERGNE ${ }^{2}$ AND ALI BOUHIFD ${ }^{1}$

${ }^{1} \mathrm{CNRS}$

${ }^{2}$ Université Paris Est - Marne La Vallée

Presenting Author: gaillard@cnrs-orleans.fr

The core - mantle differentiation in the magma ocean constitutes a major planetary event that involved two elements that are essential to life: carbon $(\mathrm{C})$ and hydrogen $(\mathrm{H})$. These two elements are conventionally classified as volatiles (ie. atmophile), but they can also evolve into being siderophile and lithophile at the extreme conditions found in planetary magma oceans. We report here a model for $\mathrm{H}$ and $\mathrm{C}$ species dissolved in silicate melts in equilibrium with iron-rich alloys under extreme conditions. This speciation model is able to reconcile and reproduce a large body of experimental data on metal-silicate partitioning for $\mathrm{H}$ and $\mathrm{C}$ at carbon-saturation. It can also predict C-undersaturated systems. At low pressure, the prevailing species in a silicate magma ocean are $\mathrm{CO} 2, \mathrm{CO}, \mathrm{H} 2 \mathrm{O}, \mathrm{H} 2$, while $\mathrm{CH} 4$ dominates at high pressure. These speciation changes explain recent experimental observations that (i) $\mathrm{C}$ evolves from being strongly siderophile at low pressure to moderately siderophile at high pressure, and (ii) $\mathrm{H}$ is not siderophile at low pressure but becomes increasingly so as pressure rises. Moreover, it shows that $\mathrm{H}$ becomes increasingly siderophile as the total $\mathrm{H}$ content of the silicate melt and $\mathrm{C}$-activity are lowered. Using this speciation model, we simulated the behaviour of $\mathrm{C}$ and $\mathrm{H}$ species in a magma ocean. $\mathrm{C}$ is in the form of dissolved $\mathrm{CO}$ and graphite in the shallow magma ocean and evolves to $\mathrm{CH} 4$ in the deep magma ocean. The enhanced $\mathrm{CH} 4$ solubility in the silicate melt at high pressure influences the fate of both $\mathrm{C}$ and $\mathrm{H}$ in large magma oceans. This model predicts that the $\mathrm{C}$ and $\mathrm{H}$ contents of the present-day Earth's depleted mantle (respectively, $37 \pm 12$ and $18 \pm 7$ ppm-wt) are compatible with metal-silicate equilibration in a deep magma ocean composed of enstatite chondrite (containing ca. 4000 ppm C and 480 ppm H). Under certain conditions, enhanced siderophile behaviour for hydrogen can lead via a runaway process to the desiccation of the magma ocean. Venus's mantle may have evolved to a dry state because of $\mathrm{H}$ incorporation in the core. This scenario is relevant to large planetary bodies and may involve massive rocky exoplanet. 